\title{
ОБОСНОВАНИЕ УРОВНЯ СУЩЕСТВЕННОСТИ ДЛЯ ФИНАНСОВОЙ ОТЧЕТНОСТИ ПО МСФО
}

\author{
(c) 2021 Качкова Ольга Евгеньевна \\ Финансовый университет, Россия, Москва \\ https://orcid.org/0000-0003-1439-2845 \\ (C) 2021 Кришталева Таисия Ивановна \\ Финансовый университет, Россия, Москва \\ https://orcid.org/0000-0003-4297-5917
}

Статья посвящена концепции существенности в МСФО. Существенность является одной из базовых качественных характеристик информации при составлении отчетности. В статье рассматриваются количественные и качественные критерии существенности, применяемые к отчетности, с учетом поправок к МСФО (IAS) 1 и МСФО (IAS) 8.

Ключевые слова: существенность; унификация определений; идентификация; оценка; прозрачность информации; качественная оценка; количественная оценка.

Задача как предоставить пользователям МСФО-отчетности релевантную и не перегруженную излишними деталями информацию без неоправданных затрат для ее составителей решается с помощью существенности. Концепция существенности отвечает на вопрос, как определить порог, при котором информация будет удовлетворять потребности различных групп пользователей финансовой отчетности, а расходы на ее сбор и раскрытие не превысят получаемых выгод.

В соответствии с действующей редакцией МСФО (IAS) 1 «Представление финансовой отчетности», «пропуски или искажения статей считаются существенными, если они по отдельности или в совокупности могли бы повлиять на экономические решения, принимаемые пользователями на основе финансовой отчетности». Существенность зависит от размера и характера пропущенной или искаженной информации, оцениваемых в контексте сопутствующих обстоятельств. При этом определяющим фактором может быть размер или характер статьи либо их сочетание.

Формулировка определения существенности, представленная в Концептуальных основах финансовой отчетности, отличается от формулировки, содержащейся в МСФО (IAS) 1 и МСФО (IAS) 8 «Учетная политика, изменения в бухгалтерских оценках и ошибки».

В МСФО (IAS) 1 представлено новое определение существенности: «Информация является существенной, если обоснованно ожидается, что ее пропуск, искажение или затуманивание может повлиять на решения основных пользователей финансовой отчетности общего назначения, вынесенные на основании такой финансовой отчетности, представляющей финансовую информацию об определенной отчитывающейся организации». Остановимся на основных особенностях нового определения.

Концептуальные основы финансовой отчетности содержат определение существенности аналогичное определению в МСФО (IAS) 1 «Представление финансовой отчетности» и MCФО (IAS) 8 «Учетная политика, изменения в бухгалтерских оценках и ошибки») [1]. В пункте 7 МСФО (IAS) 1 «Представление финансовой отчетности» понятие существенности определено, как информация является существенной, если можно обоснованно ожидать, что ее пропуск, искажение или маскировка повлияют на решения основных пользователей финансовой отчетности общего назначения, принимаемые на основе данной финансовой отчетности, предоставляющей финансовую информацию о конкретной отчитывающейся организации.

Пункт 7 МСФО (IAS) 1 поясняет: при определении того, может ли информация повлиять на решения пользователей, нужно учитывать характеристики пользователей. Согласно Концептуальным основам, финансовые отчеты составляются для пользователей с удовлетворительными знаниями о бизнесе и экономической деятельности, а также внимательно изучающих и анализирующих информацию. На 
оценку существенности влияет обоснованность предположений об экономических решениях пользователей, принятых на основе финансовой отчетности.

На практике возникают трудности с определением существенных статей. По результатам опроса, который провел Совет по МСФО, некоторые организации применяют требования МСФО к раскрытию информации механически, не вынося суждения о существенности раскрываемых статей. Некоторые сообщили, что легче раскрывать всю информацию, упомянутую в стандартах как чек-лист по раскрытиям, чем пытаться определить, какая из них существенная. По их мнению, чтобы не возникало споров с аудиторами и регуляторами, лучше раскрыть все, что требуется по МСФО [2].

Каждый класс пользователей заинтересован в получении специфической информации. В этом случае при подготовке отчетности компании следует ориентироваться на общие информационные потребности широкого круга классов пользователей.

Количественные аспекты в меньшей степени влияют на существенность информации при описании учетной политики, неопределенностей и условных фактов хозяйственной деятельности.

Примеры, в которых общая оценка существенности является наиболее чувствительной и критичной, включают:

- показатели, отражающие ковенанты по займам;

- информацию, отражающую возможное несоответствие требованиям законодательства;

- информацию, которая, как ожидается, станет важной для развития бизнеса (но несущественна для текущей отчетности);

- редкие или нестандартные операции, причины проведения которых, как обоснованно ожидается, могут повлиять на решения, принятые основными пользователями (например, по причине связанности сторон).

Требования МСФО - формировать показатели отчетности так, чтобы обеспечить надлежащую прозрачность и высококачественные данные без информационной перегрузки. А это невозможно без профессионального суждения ее составителей.

Совет по МСФО в сентябре 2017 года выпустил Практическое заявление 2 «Формирование суждений по вопросам существенности» (Practice
Statement 2 «Making Materiality Judgements»). Документ содержит необязательные указания о том, как применять концепцию существенности при подготовке финансовой отчетности: применять требования МСФО только в случае, если они существенно влияют на полный комплект финансовой отчетности, но не применять к несущественным статьям, даже если МСФО содержит список минимальных требований.

В Практическом заявлении Совет по МСФО также признал, что финансовые отчеты не могут предоставить всю информацию, которая нужна основным пользователям. В документе представлены этапы формирования суждения о конкретном уровне существенности для раскрытия и группировки информации в финансовых отчетах:

- идентификация - определение информации и ее объема для раскрытия, отвечающей требованиям МСФО;

- оценка - формирование обоснованного мнения, является ли идентифицированная на первом этапе информация существенной в количественных и качественных аспектах;

- организация - обеспечение информации, признанной на предыдущем этапе существенной, таких качественных характеристик, как прозрачность, понятность для пользователей отчетности;

- проверка - анализ финансовой отчетности на предмет перспективы и совокупности представления показателей.

В октябре 2018 года Совет по МСФО выпустил поправки к МСФО (IAS) 1 «Представление финансовой отчетности» и МСФО (IAS) 8 «Учетная политика, изменения в бухгалтерских оценках и ошибки», которыми пересмотрел определение существенности. Совет по МСФО привел в соответствие все определения существенности в разных стандартах.

При этом поправки не порождают существенных изменений в сложившейся учетной практике. Кроме унификации определения, теперь прямо упоминается недопустимость «скрытой» информации, как и «пропуск или искажение». Информация считается скрытой, если она нечеткая или теряется среди несущественной информации. Другими словами, официально признается, что пропуск информации в финансовой отчетности приравнивается к представлению информации способом, который трудно идентифицировать или понять. 
Уровень существенности уникален для каждого формирующего МСФО-отчетность предприятия или Группы компаний. Именно поэтому МСФО не дают конкретных количественных пороговых значений либо четких правил их определения. Однако приводят качественные факторы, которые следует учитывать при оценке существенности:

- позволяют ли искажения демонстрировать соответствие деятельности предприятия финансовым прогнозам - собственному, рыночному, выполненному рейтинговыми агентствами либо иными независимыми аналитиками;

- позволяют ли искажения демонстрировать соответствие нормативным требованиям, долговым обязательствам или ковенантам кредитного договора либо другим договорным требованиям;

- превращают ли искажения чистый убыток в чистый доход или наоборот;

- влияют ли искажения на ключевые коэффициенты или другие раскрытия в финансовой отчетности, на которые пользователи обращают особое внимание;

- влияют ли искажения на размеры бонусов ключевого управленческого персонала;

- искажаются ли раскрытия по сегменту деятельности;

- влияют ли искажения на раскрытие информации о сделках со связанными сторонами.

Если искажение сделано намеренно для достижения конкретного варианта раскрытия информации, то оно считается существенным независимо от суммы. Это связано с тем, что предприятие ожидало, что такое искажение повлияет на решения, принимаемые пользователями финансовой отчетности. Его не следует путать с упрощениями, принятыми организацией, так как они не предназначены для достижения конкретного представления или результата.

Отправной точкой для рассмотрения конкретной суммы уровня существенности обычно бывает определенный процент от чистой прибыли или другого крупного финансового показателя. Например, на практике используют 5 процентов чистого дохода от продолжающейся деятельности или 2-3 процента EBITDA.

Пороговые значения уровня существенности могут значительно различаться в зависимости от видов деятельности либо состава ключевых показателей эффективности, установленных для организации. Различные уровни существен- ности могут быть определены для элементов, влияющих на прибыль и убытки, и для балансовых статей. Кроме того, уровень существенности может меняться по причинам, связанным с текущим финансовым состоянием предприятия, особенно когда оно несет убытки или приблизилось к точке безубыточности.

Организации необходимо самостоятельно, ориентируясь на подходы МСФО, разработать показатель либо комплекс показателей, определяющих уровень существенности. В состав таких показателей, как правило, включается величина активов, финансового результата или источников собственных средств/капитала/чистых активов. Пороговое значение таких показателей, согласно обычаям делового оборота, устанавливается в размере от 1 до 5 процентов.

Еще один подход, встречающийся на практике,- устанавливать уровень существенности в соответствии со статьей 15.11 КоАП, где указано, что административная ответственность наступает, если налог занижен на10 процентов и больше из-за искажения данных бухгалтерского учета либо если допущено искажение любого показателя бухгалтерской (финансовой) отчетности, выраженного в денежном измерении, не менее чем на 10 процентов.

Возможны и более сложные алгоритмы расчета уровня существенности.

Предмет учета нельзя считать несущественным только потому, что он находится ниже заданного количественного порога. Требуется проводить индивидуальную и агрегированную оценки существенности предметов учета.

Так, несущественный показатель может стать существенным, если он взят вместе с другими индивидуально несущественными суммами. Поэтому важно отслеживать любые неисправленные искажения, выявленные в течение периода, чтобы оценить их совокупную существенность. С другой стороны, существенное искажение не может быть компенсировано другими существенными искажениями с зеркальным воздействием (например, завышенные доходы и расходы).

Совокупное влияние несущественных искажений предыдущих лет может стать существенным в какой-то момент.

Например, если не признать обязательство и расходы в размере 100 тыс. руб. в год за последние 10 лет, это приведет к итоговому занижению обязательств на 1000 тыс. руб. Хотя 100 
тыс. руб. обычно не могут быть существенными для какого-либо конкретного года в деятельности среднего предприятия, занижение обязательств на 1000 тыс. руб. на отчетную дату может быть признано существенным упущением. В этом случае организация не может признать обязательства и расходы в размере 1000 тыс. руб. в текущем периоде, поскольку это может существенно исказить текущие результаты. В таком случае организация ретроспективно исправляет ошибку, даже если эта ошибка не была существенной ни в каком предыдущем году.

Все сложнее при применении количественного определения существенности в промежуточной финансовой отчетности. В пунктах 23-25 МСФО (IAS) 34 «Промежуточная финансовая отчетность» указано, что существенность в промежуточной финансовой отчетности должна оцениваться со ссылкой на промежуточные результаты, а не на прогнозные результаты за полный год. Поэтому в финансовой отчетности, например, за I квартал количественный порог существенности применительно к доходам и расходам обычно составляет только четверть от уровня существенности для годовой финансовой отчетности [3].

Размер существенности, обоснованно определенный предприятием, рекомендуется согласовывать с оценкой существенности тех аудиторов, которые должны подтвердить достоверность финансовой отчетности. В противном случае возможны разногласия, урегулирование которых потребует отвлечения дополнительных ресурсов. Надо учитывать, что аудиторы в первую очередь оперируют концепцией существенности так, как она сформулирована в международных стандартах аудиторской деятельности (MCA).

У аудиторов основу определения размера уровня существенности также составляет профессиональное суждение. Иными словами, в MCA также нет конкретных указаний по расчету уровня существенности, они только расставляют приоритеты и указывают аудитору, на что нужно обратить внимание. Например, необходимо учитывать:

- показатели, которые больше других интересуют пользователей финансовой отчетности организации;

- этап жизненного цикла развития бизнеса;

- экономическую среду работы организации;
- структуру собственности и способ финансирования организации;

- изменчивость выбранного показателя в течение отчетного периода. Например, если прибыль до налогообложения от операционной деятельности волатильная, более подходящими контрольными показателями могут оказаться валовая прибыль или совокупная выручка (п. А4, A5 MCA 320).

Например, MCA 320 определяют в качестве примеров надлежащих контрольных показателей: прибыль до налогообложения, выручку, валовую прибыль и совокупные расходы, собственный капитал или стоимость чистых активов.

Аудиторы в основном применяют сложные математические формулы расчета уровня существенности, в том числе с использованием специальных программ (IT Audit, AuditXР и др.). Вводятся показатели вероятности допущения ошибок, вероятности их непопадания в аудиторские выборки и т.п.

Важнейший элемент подготовки отчетности по МСФО - профессиональное суждение. Считается, что если применять обоснованные суждения, то требования МСФО к раскрытию информации могут быть уменьшены до разумного количества. Однако компании всегда необходимо учитывать, поймут ли основные пользователи финансовой отчетности ту часть информации, которая не раскрыта в деталях.

Аналогичным образом суждения относительно существенности должны учитывать количественные и качественные характеристики фрагмента информации, его актуальность и необходимость для основных пользователей финансовой отчетности. Управленческие суждения должны быть беспристрастными, нейтральными и разумными. При этом существенность оценивается в контексте финансовой отчетности в целом, будь то ошибки или упущения в признании или оценке фактов хозяйственной деятельности, в представлении или раскрытии информации. Так, пропущенное раскрытие, которое может быть существенным для понимания информации о компенсациях, основанных на акциях компании, может тем не менее быть несущественным для понимания финансовой отчетности в целом.

Ошибки, даже несущественные, сделанные для достижения определенного результата, запрещены. Непредумышленные существенные 
ошибки следует своевременно исправить. МСФО не могут запретить раскрывать несущественные аспекты финансово-хозяйственной деятельности, но не поощряют такую практику. Кроме того, новое определение понятия «существенность» ясно дает понять, что нельзя за объемом раскрытия несущественных данных скрывать существенную для основных пользователей отчетности информацию.

Не допускается вуалировать существенную информацию несущественными данными, тем самым делая отчетность менее понятным. Если информация несущественна, ее не нужно раскрывать, несмотря на требования соответствующих стандартов. И наоборот, если стандарт не требует определенных раскрытий, но они необходимы для понимания сути финансовых данных, такую информацию нужно раскрыть. Например, стандарты по учету финансовых инструментов предполагают большой объем раскрытий, но, если у организации доля финансовых активов в балансе несущественна, раскрытия можно не делать. Если валютная выручка организации заметно изменилась по сравнению с прошлым годом, важно указать пользователю отчетности на причины, хотя прямых требований об этом в стандартах нет.

Уровень существенности составителя отчетности не должен быть выше, чем уровень существенности, определенный аудитором [4].

Ошибки в финансовой отчетности по МСФО могут быть трех типов:

- несущественные, ниже минимального уровня корректировок;

- находящиеся в интервале между минимальным уровнем корректировок и уровнем существенности;

- превышающие уровень существенности или существенные по качественным показателям.

Так ошибки в вопросе обесценения активов довольно часты и нередко приводят к необходимости значительных корректировок финансовой отчетности. Вопрос обесценения требует профессиональных суждений руководства на основе обоснованных расчетов и допущений.

Подходы к оценке обесценения финансовых и нефинансовых активов различаются. Обесценение финансовых активов с 1 января 2018 года регулируется МСФО (IFRS) 9 «Финансовые инструменты». Обесценение нефинансовых активов регулируется МСФО (IAS) 36 «Обесценение активов». В целом все ошибки можно свести к отсутствию или необоснованному упрощению учетной политики по анализу признаков обесценения, которая также должна включать расчетные модели. В результате обесценение активов может вообще не признаваться при наличии объективных признаков обесценения либо признаваться по заниженной сумме в результате неверного расчета.

Например, в учетной политике по МСФО в части обесценения финансовых активов, учитываемых по амортизированной стоимости (займы, дебиторская задолженность), могут быть не определены порядок и критерии оценки платежеспособности контрагентов, методы оценки вероятности дефолта, величины и сроки погашения задолженности, расчета эффективной ставки процента, применяемой для дисконтирования денежных потоков, определения периода дисконтирования и т.п., и, соответственно, не делаться необходимые анализ и расчеты.

MCФO (IFRS) 9 требует наличия математических моделей оценки обесценения финансовых активов на основе анализа статистики потерь, вероятности дефолта и прогнозных данных по состоянию должника и его отрасли в предполагаемую дату возможного дефолта [5].

Что касается нефинансовых активов, прежде всего основных средств и нематериальных активов, то в учетной политике по МСФО следует установить признаки обесценения и порядок их оценки на обесценение.

Организация должна на конец каждого отчетного периода оценить, нет ли каких-либо признаков обесценения активов. В случае наличия любого признака организация должна оценить возмещаемую сумму актива (п. 9 МСФО (IAS) 36). МСФО (IAS) 36 определяет возмещаемую сумму как справедливую стоимость актива или генерирующей единицы за вычетом затрат на выбытие либо как ценность использования в зависимости от того, которая из данных величин больше. Поэтому не всегда требуется определять и справедливую стоимость актива за вычетом затрат на выбытие, и ценность использования. Если один из показателей превосходит балансовую стоимость актива, то актив не обесценен, что исключает необходимость в оценке другого показателя (п. 19 МСФО (IAS) 36).

Определить справедливую стоимость актива нередко быстрее и проще, чем рассчитать ценность его использования. Поэтому оптималь- 
ным вариантом для многих ситуаций может быть оценка справедливой стоимости с привлечением независимого оценщика или собственными силами. МСФО не требуют обязательного привлечения независимого оценщика, бывает достаточно профессионального суждения штатных специалистов, которые должны подготовить мотивированное суждение, включив в него анализ рынка, разумные допущения и обоснованные расчеты. Чтобы минимизировать ошибки, организации необходимо тщательно изучить требования МСФО (IAS) 36 и МСФО (IFRS) 9 (для финансовых активов) к вопросам обесценения активов и разработать соответствующие учетные политики и методики.

Если в соответствии с учетной политикой актив отражается по переоцененной стоимости, то необходимо периодически его переоценивать и отражать результаты в отчетности.

Чаще встречаются ошибки, связанные с завышением справедливой стоимости активов, но бывают и случаи занижения. В соответствии с пунктом 31 МСФО (IAS) 16 «Основные средства» переоценка должна производиться достаточно регулярно, чтобы не допустить существенного отличия балансовой стоимости актива от той, которая была бы определена с использованием справедливой стоимости по состоянию на дату окончания отчетного периода [5].

В соответствии с пунктом 34 МСФО (IAS) 16 частота проведения переоценки зависит от изменения справедливой стоимости переоцениваемых объектов основных средств. Если справедливая стоимость переоцененного актива существенно отличается от его балансовой стоимости, требуется дополнительная переоценка [6].

Некоторые объекты основных средств характеризуются значительными и волатильными изменениями справедливой стоимости, что вызывает необходимость в ежегодной переоценке.

Проведение таких частых переоценок не требуется для объектов основных средств, справедливая стоимость которых подвергается лишь незначительным изменениям. В таких случаях необходимость переоценки может возникать только каждые три-пять лет.

Частота проведения переоценки требует мотивированного суждения. При значительных колебаниях рынка основных средств от года к году, непроведение ежегодной переоценки было бы ошибкой.

Кроме того, ошибочно сохранять неизмен- ную стоимость основных средств при очевидных признаках существенного обесценения из-за рыночных факторов. При определении справедливой стоимости переоцениваемых нефинансовых активов важно тщательно подготовить профессиональное мотивированное суждение и согласовать его с аудитором. Отчет независимого оценщика важен, но его стоимость может быть скорректирована в процессе подготовки финансовой отчетности по МСФО.

Одна из распространенных ошибок - несвоевременное отражение операций. Например, выручка или расходы, относящиеся к отчетному периоду, отражаются в следующем отчетном периоде. Это может быть связано с поздним получением подтверждающих документов или отсутствием на момент подготовки финансовой отчетности решений руководства по тем или иным статьям доходов/расходов.

Здесь нарушается один из базовых принципов подготовки отчетности - организация должна составлять свою финансовую отчетность, за исключением информации о денежных потоках, методом начисления (п. 27 MCФО (IAS) 1), который отражает влияние операций, а также прочих событий и обстоятельств на экономические ресурсы отчитывающейся организации и предъявленные к ней требования в тех периодах, в которых данные последствия имеют место быть, даже если являющиеся их следствием денежные поступления и выплаты происходят в другом периоде (п. ОВ17 Концептуальных основ финансовой отчетности).

Организация должна предусмотреть в своей учетной политике методы оценки сумм доходов и расходов, относящихся к отчетному периоду и удовлетворяющих критериям признания, даже если на момент подготовки финансовой отчетности не получены все документы или нет точной информации по суммам. Например, в феврале или марте еще может быть не известна точная сумма премий, причитающихся сотрудникам. Однако это не значит, что не нужно делать начислений, которые можно определить на основе информации прошлых периодов.

Каждый МСФО содержит список требований к раскрытию информации. Они могут быть больше или меньше в зависимости от конкретного МСФО. Важно понимать, что требования к раскрытию информации в примечаниях такие же строгие, как и к отчетам о финансовом положении и о совокупном доходе. 
Оценка существенности информации должна проводиться для разных частей отчетности. Следует проанализировать: подлежит ли информация отдельному представлению в основной финансовой отчетности, и если да, то как, подлежит ли информация отдельному представлению в примечаниях к финансовым отчетам, и если да, то как, изменится ли вывод по двум преды- дущим вопросам после проверки полного комплекта финансовых отчетов, можно ли изложить информацию более корректно и понятно.

При принятии решений руководство должно опираться в большей степени не на количественное значение показателя существенности, а на профессиональное суждение о характере информации.

\section{Библиографический список}

1. Губа О.П., СевостьяноваЕ.С., Штепа А.А. Бухгалтерская отчетность как значимый инструмент оценки сбалансированности развития предприятий//Символ науки: Международный научный журнал. № 3. 2020. C. $36-43$

2. МСФО в России как новая интеллектуальная среда, взгляд профессионального сообщества. Монография/ колл. авторов.- М.: Кнорус, 2018. 200 с.

3. Домбровская E.Н. Обеспечение существенности показателей бухгалтерской (финансовой) отчетности//Аудит. -2019 . № 5. С.4-7

4. Абдуллин Д.М., Демина И. Д. Особенности определения уровня существенности при планировании и проведении аудита публичной нефинансовой отчетности организаций//Учет, анализ, аудит. 2019. № - С.87-94

5. МСФО и Федеральные стандарты бухгалтерского учета: системное развитие, проблемы взаимодействия. Монография/под ред. Г. И. Алексеевой, Е. Н.Домбровской. - М.: КНОРУС, 2019.-206с.

6. Медведев М.Ю. «Представление финансовой отчетности». Учет имущества согласно МСФО: переводы на человеческий. - М.: Изд-во «ДМК Пресс». 2013. 286 с. 